error through millions of years of natural selection. This is a familiar strategy of biology" [p. 77].

The digital computer is rejected as a model of the brain in favour of a scheme involving many special processors probably consisting of interacting nets of neurons. Cortical organization is seen as being dictated by the need for short pathways and the efficient use of a limited (though enormous) number of neurons. This wiring requirement produces specialized, highly interactive modules linked to nearby functionally related ones, like 'villages' within a city.

Crick argues that far more detailed knowledge of human brain anatomy particularly the cortical layers - is required to make any real progress in locating the main sites of possible "awareness neurons". His favourite candidates are the inner cortical layers and subcortical structures, especially the 'gateway to the cortex', the thalamus. And because many specialized visual processors deal separately with form, movement, depth, colour and so on, there is the 'binding problem' of how their contributions come together to give coherent, vivid perceptions. Crick thinks that neural mechanisms of attention may hold the key, with neural oscillations as the basis of selective attention and captured synchronous outputs of processors underlying binding.

But what of qualia? Why is red red? Crick would seem to agree with Stuart Sutherland's statement: "Consciousness is a fascinating but elusive phenomenon; it is impossible to specify what it does, or why it evolved. Nothing worth reading has been written on it." But by seeking neural correlates, he hopes to capture consciousness from philosophy. And by rejecting special properties (as in vitalism), he emphasizes emergence, pointing out that novelty generated by combinations of particles, or properties, even at the molecular level, is the essence of chemistry and life. Here 'emergence' does not mean mysteries popping out of the undergrowth; it means that with a sufficient understanding of interactive processes, we should come to understand why a complex whole has properties its parts lack on their own, and how the parts are modified by the context in which they lie.

This is a flexible kind of atomism. Perhaps the ultimate aim is to derive a conceptual model for understanding the emergence of consciousness from the physics of neurons. All this from DNA, through the evolution of intelligence. Dare we call it Darwinian Neural Awareness?

Richard L. Gregory is in the Department of Psychology, University of Bristol, Bristol BS8 21H, UK.

\title{
The talking ape
}

Christopher Longuet-Higgins

The Language Instinct: How the Mind Creates Language. By Steven Pinker. Morrow: 1994. Pp. 494. \$23. To be published in the United Kingdom by Viking on 11 April at $£ 20$.

HERE at last is a marvellously readable book about language, written by a real expert. Steven Pinker tackles with wit and erudition the kinds of question everyone asks about language. Why do immigrants have such trouble learning a new tongue, only to have their children ridicule their grammatical mistakes? Why is the Maple Leafs hockey team not called the Maple Leaves? Have scientists actually succeeded in reconstructing the first language

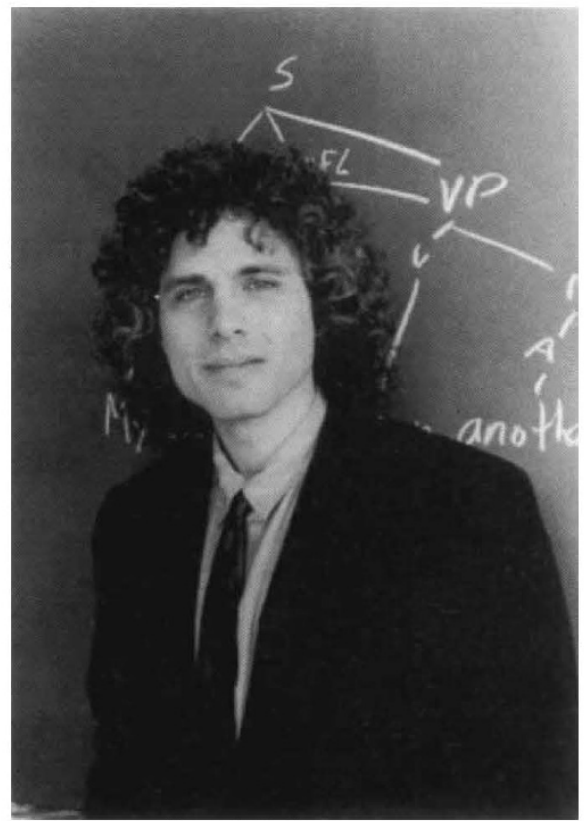

Pinker - no linguistic hang-ups.

spoken on Earth? Are there genes for grammar? Can chimpanzees really learn human sign languages? How could language have evolved? Does a person's language control the way he or she thinks? Is the English language gradually falling apart?

To these questions Pinker brings not only an expertise in linguistics and psychology and a wide knowledge of biology, but also an ability to understand the ordinary person's linguistic hang-ups and to shake them loose with gentle ridicule. Here (slightly condensed) is the opening of his chapter on "The Language Mavens" (the word 'maven' was coined by the critic William Safire for a self-appointed regulator of the English language):

Imagine you are watching a nature documentary. The video shows the usual gorgeous footage of animals in their natural habitats. But the voiceover reports some disturbing facts. White-crowned sparrows carelessly debase their calls, and the song of the humpback whale contains several wellknown errors. Your reaction would probably be, What on earth could it mean for the song of the humpback whale to contain an 'error'? Who is this announcer, anyway?

All the best writers in English, at all periods, including Shakespeare and most of the mavens themselves, have been among the most flagrant flouters [of the mavens' rules]. The rules conform neither to logic or to tradition, and if they were ever followed they would force writers into fuzzy, clumsy, wordy, ambiguous, incomprehensible prose, in which certain thoughts are not expressible at all.

The principal theme of The Language Instinct is implicit in its title. Human language defies explanation as the automatic response of a general-purpose brain to the complex stimuli of early childhood; it must, as Noam Chomsky has always insisted, be a largely inherited faculty. But while Chomsky is fiercely agnostic about the evolutionary origin of language, Pinker makes a convincing case that language evolved by a fully Darwinian mechanism, like the elephant's trunk. (Those who have lost their childhood wonder at this astonishing proboscis will regain it as soon as they read the breathtaking first paragraph on page 332 .)

There are other points at which Pinker departs from Chomskian orthodoxy, most notably in postulating a mental language - "mentalese" - in which we marshal our thoughts before expressing them in, say, English, and into which we translate what other people say to us. The value of such a hypothesis depends, of course, on its predictive power, and one may prefer an account of thinking more along the lines laid down in Philip Johnson-Laird's influential book Mental Models (Harvard University Press/Cambridge University Press, 1983). But at least the concept of an internal language of the mind seems preferable to the simplistic idea that Englishmen think in English while Frenchmen think in French - a hypothesis that creates acute problems about how chess players or tennis players or flute players might think, and how people manage to translate, however awkwardly, from one language into another.

Whatever its eventual impact on linguistics and psychology, The Language Instinct will undoubtedly be greeted as a distinguished contribution to the lay understanding of science. In the past, linguists have been less effective as communicators than, say, astronomers or biologists, but now the educated layman will have no excuse for imagining that 'deep structure' is essentially the same thing as 'universal grammar'. (There is an excellent glossary in which such misconceptions can be quietly sorted out.) And Pinker is determined to give us some hard, detailed information to get our minds 
into. In the Bantu language Kivunjo, he tells us, the verb form Näikìmlyïà, meaning "He is eating it for her", is one of about half a million possible forms, which native speakers have no trouble in assembling on the fly from bits and pieces such as these:

$\mathrm{N}$ - A marker indicating that the word is the 'focus' of that point in the conversation.

-ä- A subject agreement marker, identifying the eater as falling into class 1 of the 16 gender classes, 'human singular'. Other genders (kinds, not sexes) embrace nouns that pertain to several humans, thin or extended objects, objects that come in pairs or clusters, the pairs or clusters themselves, instruments, animals, body parts, diminutives (small or cute versions of things), abstract qualities, precise locations and general localities.

-i- Present tense. Other tenses in Bantu can refer to today, earlier today, yesterday, no earlier than yesterday, yesterday or earlier, in the remote past, habitually, ongoing, consecutively, in the future, at an indeterminate time, not yet and sometimes.

-kì- An object agreement marker, in this case indicating that the thing eaten falls into gender class 7

And so on.

One of the mysteries Pinker does not resolve for the inquisitive reader is the precise relationship between the earlyand the late-flowering varieties of Chomskian linguistic theory. His reasons may be diplomatic, or simply expository: a fear of the pedagogic confusion that might result from attempting to superimpose the most recent version of "GB theory" on the "Xbar theory" to which he has so carefully introduced the reader. Perhaps he merely felt it wiser to hide the antics of the professional linguists from the searching gaze of student innocence.

For all other readers, The Language Instinct will illuminate every facet of human language: its biological origin, its uniqueness to humanity, its acquisition by children, its grammatical structure, the production and perception of speech, the pathology of language disorders and the unstoppable evolution of languages and dialects. With its wealth of examples, its flawless typesetting, its wide-ranging bibliography and its irresistible good humour, Pinker's book is certain to increase its readers' respect for the amazing natural phenomenon that the author and his colleagues have made their life's (to a maven, lives'?) study.

Christopher Longuet-Higgins is in the Laboratory of Experimental Psychology, University of Sussex, Falmer, Brighton BN1 9QG, UK.

\section{Reactions speak louder than words}

\section{Roald Hoffmann}

La Parole des Choses. By Pierre Laszlo. Hermann: 1993. Pp. 320. FFr160.

THERE has always been a link between language and chemistry. Lavoisier begins his revolutionary Traité Elémentaire de Chimie with a quote from the Abbe de Condillac: "We think only through the medium of words. Languages are true analytical methods." Lavoisier then reflects on his own work: "Thus, while I thought of myself employed only in forming a Nomenclature... my work transformed itself by degrees, without my being able to prevent it, into a treatise upon the Elements of Chemistry". The distinguished European writer Elias Canetti, author of a remarkable study of mass behaviour, Crowds and Power, and a striking novel of the 1930s, Auto da Fé, earned a PhD in chemistry. He credits chemistry with teaching him the importance of linguistic structure. And Benjamin Lee Whorf, the great American linguist who made a case for language shaping culture, trained as a chemical engineer at the Massachusetts Institute of Technology. Whorf was not averse to "an occasional chemical simile". In an essay on languages and logic he writes: "the way the constituents are put together in these sentences of Shawnee and Nootka suggests a chemical compound, whereas their combination in English is more like a mechanical mixture".

Pierre Laszlo's rich and original book explains the link between language and chemistry. Laszlo makes an analogy between molecules and their transformations on one hand and linguistic structures such as morphemes, phonemes, ideograms and pictograms, transformations of mode and description on the other. If the latter sound abstruse to a chemist, imagine what sense a functional group, elementary reactions, $\mathrm{C}_{6} \mathrm{H}_{6}$ or a benzene ring drawn out (of course, without a $\mathrm{C}$ or $\mathrm{H}$ indicated) would make to a linguist other than the late Whorf.

La Parole des Choses (perhaps one way to translate the title is "The Way Things Speak", but that doesn't capture the allusion to the structuralist and literary theory use of parole) is actually two books. The working out of the language-chemistry analogy is one theme that runs through this readable volume. Another theme, interwoven, is simply that of the beauty of chemistry. The logic of the molecular science is masterfully explicated, with few compromises, for an intelligent reader outside chemistry. For instance, the book contains a beautiful discussion of nitrogen inversion, the best short introduction to nuclear magnetic resonance I've read and even a brief account of femtosecond reactions. But consistent with Laszlo's broad cultural theme, these expositions are juxtaposed with, respectively, a quote from Gérard de Nerval (a nineteenth-century French poet and writer), a touching retelling of some of Laszlo's misadventures in taking his first NMR spectrum in 1961, and an excerpt from Blake's Milton.

Insights and information abound. The linguistic analogy builds convincingly, but one does not have to buy into it to appreciate the capsule description of the economics of the perfume industry (and the composition of "Obsession") or the surprising use by Hegel of Berzelius's electrochemical theory or the prolonged alchemical and chemical use of the word menstruum for solvent.

Let me see if I can put my finger more precisely on the value in this book. To deconstruct scientific texts is so easy, too easy. Ditto for the use of literary allusions to pretty up science writing. Laszlo does something more - he sets up an intriguing analogy, of the processes of language and chemistry, and lets the analogy illuminate each field.

Roald Hoffmann is in the Department of Chemistry, Cornell University, Ithaca, New York 14853-1301, USA.

\section{Linguistic geography}

\section{Mark Pagel}

Atlas of the World's Languages. Edited by Christopher Moseley and R. E. Asher. Routledge: 1994. Pp. 372. £395, $\$ 599.95$.

FIFTEEN years ago, one respected encyclopaedia of the world's languages placed the number of known extant human languages at around 4,550. By 1984 a new survey found that at least 5,450 different languages were being spoken on Earth. The number rose to 6,170 by the time of the appearance of the eleventh edition of Ethnologue: Languages of the World (edited by B. F. Grimes, Summer Institute of Linguistics, 1988), and to more than 6,500 by the twelfth edition. The true number is probably even higher. This diversity of languages, all of them spoken by the same species, is testimony to the human - one might say - compulsion to speak. Unlike chimpanzees, which need daily operant prodding to use even a small repertoire of words, it is difficult to stop humans from using language: linguists 